Received $12^{\text {th }}$ August 2019 Accepted $06^{\text {th }}$ October 2019 www.ijpefs.com

\section{Comparison of Nutrition Status and Knowledge Level of Sports Trainers and Individuals Attended with Nine-Round Fitness Sports}

\author{
A. Humeyra Islamoglu a, ${ }^{*}$, I. Aycan Basoglu a, Aleyna A. Ozbey b, Feyza Tosya b, \\ F. Esra Gunes a

\footnotetext{
a Marmara University Faculty of Health Sciences, Department of Nutrition and Dietetics, Turkey.

a Graduates of Marmara University Faculty of Health Sciences, Department of Nutrition and Dietetics, Turkey.

*Corresponding Author Email: humeyra.bicer@gmail.com
}

Abstract: The aim of this study was to determine and evaluate the nutritional knowledge levels and nutritional status of the sports trainers and individuals doing nine-round fitness sports, and compare the relationship between two groups. One hundred individuals doing sports and 10 trainers were included in the study. A questionnaire about general demographic information, anthropometric measurements, nutritional habits and sporting status were applied to the participants. In addition, 1-day retrospective food consumption record was taken to evaluate the intake levels of macro and micronutrients, and The Basic Nutrition Knowledge Level for Adults (YETBID) Scale was applied to measure the nutritional knowledge of the participants. The mean energy (kcal), protein (g), fat (g) and carbohydrate (g) intakes were found to be $1930 \pm 832,6,117,8 \pm 61,3,88 \pm 34,5$, $159 \pm 111,1$ for trainers and $1465 \pm 533,81,8 \pm 33,9,66,6 \pm 26,4,128 \pm 76,9$ for individuals doing sports, respectively. A significant difference was found between two groups in terms of energy intakes $(p=0,042)$ whereas, no significant difference was found between the levels of macro nutrient intakes between trainers and individuals doing sports $(p>0.05)$. According to the YETBID scores, it was found that the total score of individuals doing sports was significantly higher than trainers' ( $p=0.037)$. It was concluded that the level of nutritional knowledge of sports trainers and individuals doing sports did not affect the nutritional status. Furthermore, dietitians should be present at sport centers and nutrition trainings should be arranged in order to prevent improper nutrition practices.

Key Words: Nutrition Knowledge, Nutritional Status, Eating Habits, Fitness

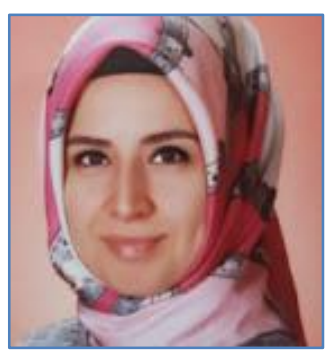

Dr. Ayse Humeyra Islamoglu gained her Ph.D. at the Institute of Nutrition and Dietetics of Medipol University (Turkey) and currently working as a Research Assistant in the Department of Nutrition and Dietetics, Marmara University (Turkey). Her research areas include: nutrition in neurological disorders, sports nutrition, food technology and analysis. Her latest article about sports nutrition is "Nutrition sport performance. Considerations for Athletes with Physical Disabilities".

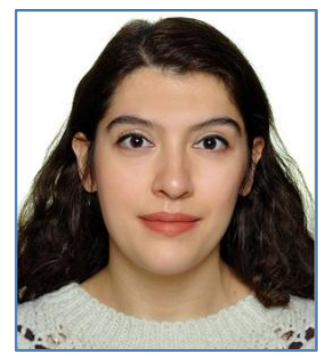

Ms. Izel Aycan Basoglu received her M.Sc. in Nutrition and Dietetics at Institute of Health Sciences of Marmara University in 2019. At present she is working as Research Assistant in the Department of Nutrition and Dietetics. Her research interests' focus on nutrigenomics, sport nutrition, Her master thesis was about how nutrition and genotype-phenotype effect 


\section{A. Humeyra Islamoglu et al.,/2019}
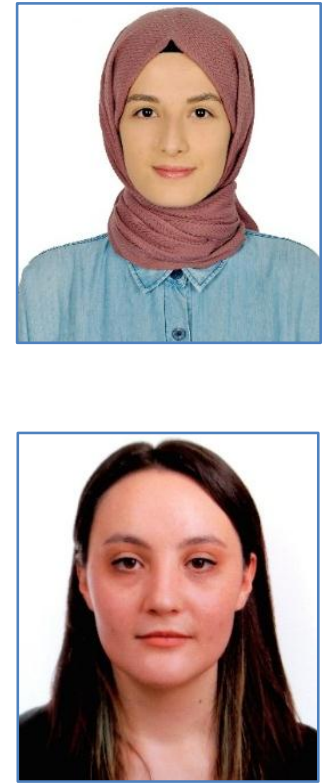

Ms. Aleyna Ozbey graduated from Marmara University, Department of Nutrition and Dietetics. Her research interests are sports nutrition, mother and child nutrition, enteral and parenteral nutrition.

\section{Ms. Feyza Tosya graduated} from Marmara University, Department of Nutrition and Dietetics. Her current research focus on clinical nutrition, sports nutrition and nutrition in pediatric diseases.

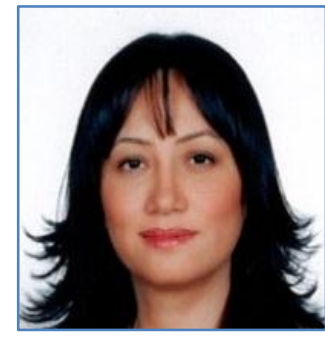

Dr. Fatma Esra Gunes is the Head of the Nutrition and Dietetics Department of Marmara University. Her major research interests are public health, nutrition epidemiology, nutrigenetics and epigenetics, clinical nutrition and sport nutrition.

\section{Introduction}

Nowadays, many individuals prefer sports centers for sports. The main objectives of the individuals involved in nutrition are; is to obtain enough nutrients to optimize health, fitness or sports performances. It is considered that trainers provide information about sports branches, exercise, nutrition and ergogenic support to individuals doing sports in sports centers $[1,2]$. However, today there is a lot of misinformation about nutrition. It is thought that this situation affects individuals who do sports and their nutritional status. As a matter of fact, it is known that many people who do sports do not have enough information about balanced nutrition and that wrong practices are common among athletes and may have dangerous consequences [3]. Reasons such as lack of nutritional information, individuals' interest in making changes in diet, people's economic status, lack of time prevent healthy eating [2]. In the studies, it is emphasized that coaches and athletes need guidance on nutrition $[4,5]$.

The aim of this study is to investigate the relationship between nutritional knowledge and nutritional status of sports instructors and recreational fitness athletes working with them. In addition, it is aimed to measure the nutritional knowledge level of individuals doing sports and to determine their nutritional status within the scope of the type of sports.

\section{Materials and Methods}

\subsection{Type and Sample of Research}

This study is a descriptive observational study conducted in 5 Nine-Round Fitness Sports Centers in Istanbul between 01.04.2019 and 01.06.2019. Nutritional information levels and nutritional statuses between identified sports trainers and recreational athletes working with them are defined comparatively. In this study, the sport chosen as the sample is based on strength and endurance and consists of 110 individuals including 10 sports instructors and 100 athletes.

\subsection{Collecting Research Data}

In this study, a questionnaire consisting of a total of 31 questions including; personal information, sociodemographic characteristics, anthropometric measurements, smoking and alcohol use, exercises and nutrition was used. A one-day retrospective food consumption record form is included in the questionnaire. The questionnaire was administered to the participants by face-to-face interview technique over a 25-minute period. The questions in this questionnaire were created by the research team. 


\section{A. Humeyra Islamoglu et al.,/2019}

\subsection{Evaluation of Food Consumption Records}

One-day food consumption records of all participants were taken; energy, macro and micro nutrient intakes were calculated by using BeBiS 7.2 program (Nutrition Information System, Stuttgart, Germany). The energy and macro nutrient requirements of athletes have been compared with the recommendations of the International Sport Nutrition Community (ISSN). The reference value range for the energy requirement is $25-35 \mathrm{kcal} / \mathrm{kg}$; the requirement of macro nutrients was calculated as $45-55 \%$ from carbohydrate, $10-15 \%$ from protein and $25-35 \%$ from fat [6]. Turkey Nutrition Guide was accepted as references for micronutrients [7]. The daily consumptions were compared with the reference values and the meeting percentages were calculated.

\subsection{Determination and Evaluation} Anthropometric Measurements

Body weight and height were recorded according to the participants' declarations and the Body Mass Index (BMI) value was calculated by dividing the body weight $(\mathrm{kg})$ by the length $(\mathrm{m})$ square.

\subsection{Assessment of Basic Nutrition Knowledge Level for Adults Scale}

The Basic Nutrition Knowledge Level for Adults (YETBID) scale includes basic nutrition and food-health information sections. Participants gave answers as; strongly agree, agree, neither agree nor disagree, disagree, strongly disagree. The sum of the scores obtained from each question gives the scale score. The highest score under the heading of basic nutrition and food health is 80 points. Poor for participants below 45 points, moderate for participants in the 45-55 range, good for participants with a score of 56-65, very good for participants with a score of over 65 [8].

\subsection{Statistical Evaluation of Data}

The data obtained from the study were analyzed using SPSS 16.0 (Statistical Package for the Social Sciences, Inc., Chicago, IL, USA). Chi-square test was used to examine qualitative variables. The compatibility of the variables to the normal distribution was checked by Kolmogorov Smirnov test. T-test and ANOVA test were performed in independent groups, provided that it was compatible with normal distribution. Mann-Whitney U Test and Kruskal Wallis analysis methods were applied in case of non-compliance with normal distribution. If the data had a normal distribution, Pearson correlation coefficient was used in order to determine the relationship between two continuous variables, and Spearman correlation coefficient was used when the data was not distributed normally. Results were evaluated at 95\% confidence interval and $\mathrm{p}<0.05$ significance level.

\section{Results}

Twenty percent of the trainers $(n=2)$ were women and $80 \%(n=8)$ were men; $46 \%(n=46)$ of the of athletes were women and $54 \%(n=54)$ were men. Participants consisted of individuals aged between 19-45. The mean age of the sports trainers was 27.6 \pm 4.1 , while the mean age of the athletes was $30.8 \pm$ 6.3. It was observed that most of the athletes and sports trainers $(64 \%, 80 \%)$ have undergraduate degrees. The anthropometric measurements participants are summarized in Table 1.

\subsection{Nutritional Habits}

$58.4 \%$ of the participants $(n=66)$ stated that they skipped meals and the distribution of the number of main meals and snacks is given in Table 2 . When the number of daily main meal and snack consumptions of the participants were compared; no significant difference was found between the number of main meals of sports trainers and athletes ( $p>0.05)$, whereas, it was found that the number of daily snacks of sports trainers was significantly higher than the athletes $(p=0.001)$.

It was observed that $55 \%$ of individuals doing sports and $90 \%$ of trainers skipped meals and $77 \%$ of trainers skipped lunch. The lack of sufficient time of the trainers due to working conditions was determined as the main reason for skipping meals. When BMI values of the participants were compared with meal skipping status, BMI values of the participants who skip meals $\left(25.1 \pm 3.3 \mathrm{~kg} / \mathrm{m}^{2}\right)$ were 


\section{A. Humeyra Islamoglu et al.,/2019}

significantly higher than those who do not skip meals $\left(22.9 \pm 3.2 \mathrm{~kg} / \mathrm{m}^{2}\right)(\mathrm{p}=0.049)$.

Table 1 Anthropometric measurements of participants

\begin{tabular}{|l|c|c|c|}
\hline & Trainers & Individuals Doing Sports & \\
\hline & Mean \pm SD & Mean \pm SD & 0,233 \\
\hline Age (year) & $27.6 \pm 4.1$ & $30.8 \pm 6.3$ & $\mathbf{0 , 0 2 8}$ \\
\hline Height $(\mathrm{cm})$ & $178.0 \pm 9.4$ & $171.7 \pm 8.02$ & 0,139 \\
\hline Weight $(\mathrm{kg})$ & $78.3 \pm 9.4$ & $71.2 \pm 14.7$ & 0,328 \\
\hline BMI $\left(\mathrm{kg} / \mathrm{m}^{2}\right)$ & $24.6 \pm 2.1$ & $23.8 \pm 3.6$ & 0,193 \\
\hline Fat Mass $(\%)$ & $14.0 \pm 3.7$ & $17.5 \pm 4.1$ & \\
\hline
\end{tabular}

Table 2 Evaluation and comparison of meal numbers of trainers and individuals doing sports

\begin{tabular}{lccc}
\hline & Trainers & \multicolumn{2}{c}{ Individuals Doing Sports } \\
\cline { 2 - 3 } & Mean \pm SD & Mean \pm SD & $p$ \\
\cline { 2 - 4 } Main Meals & $2,9 \pm 0,7$ & $2,6 \pm 0,5$ & 0,239 \\
Snacks & $2,4 \pm 0,7$ & $1,4 \pm 0,8$ & $\mathbf{0 , 0 0 1}$ \\
\hline
\end{tabular}

Table 3 Daily energy, macro and micro nutrient intake of sports trainers and athletes

\begin{tabular}{|c|c|c|c|c|c|c|c|}
\hline & \multicolumn{3}{|c|}{ Trainers } & \multicolumn{3}{|c|}{ Individuals Doing Sports } & \multirow[b]{2}{*}{$\mathrm{p}$} \\
\hline $\begin{array}{l}\text { Energy \& Nutrient } \\
\text { Intakes }\end{array}$ & Mean \pm SD & Min. & Max. & Mean \pm SD & Min. & Max. & \\
\hline Energy (kcal) & $1930 \pm 832,6$ & 923,1 & 3870,4 & $1465 \pm 533$ & 609,1 & 3748 & 0,042 \\
\hline Protein (g) & $117,8 \pm 61,3$ & 31,2 & 21,5 & $81,8 \pm 33,9$ & 20,6 & 216,3 & 0,099 \\
\hline Fat (g) & $88 \pm 34,5$ & 39,7 & 39,7 & $66,6 \pm 26,4$ & 21 & 192,2 & 0,016 \\
\hline Carbohydrate (g) & $159 \pm 111,1$ & 74,9 & 441,7 & $128 \pm 76,9$ & 37 & 561 & 0,334 \\
\hline Vitamin A (mcg) & $1344 \pm 554$ & 241,6 & 2153 & $1087 \pm 634$ & 179,3 & 4115,4 & 0,221 \\
\hline Vitamin E (mg) & $21,6 \pm 11,2$ & 2 & 41,2 & $16 \pm 8,8$ & 2,3 & 60 & 0,065 \\
\hline Folic Acid (mcg) & $290 \pm 139,3$ & 92,4 & 499,4 & $240 \pm 84$ & 80 & 499,4 & 0,103 \\
\hline Niacin (mg) & $44 \pm 23$ & 15,4 & 73,2 & $30,2 \pm 14$ & 8,3 & 87 & 0,006 \\
\hline Vitamin C (mg) & $63,6 \pm 29,7$ & 17,7 & 114,6 & $83,5 \pm 59,4$ & 0 & 387,5 & 0,299 \\
\hline Vitamin $B_{6}$ (mg) & $1,76 \pm 0,77$ & 0,7 & 2,7 & $1,3 \pm 0,5$ & 0,5 & 4,3 & 0,136 \\
\hline Vitamin $B_{12}(\mathrm{mcg})$ & $8,7 \pm 4,6$ & 1,9 & 18,4 & $5,4 \pm 3,5$ & 0 & 19,1 & 0,007 \\
\hline Sodium (mg) & $3151 \pm 2336$ & 501,1 & 9112,3 & $3114 \pm 1278$ & 537,1 & 6443 & 0,935 \\
\hline Calcium (mg) & $787 \pm 484$ & 246,8 & 1723,5 & $700 \pm 357$ & 158 & 1757 & 0,476 \\
\hline Magnesium (mg) & $321 \pm 137,9$ & 138,8 & 524 & $263 \pm 93$ & 89,4 & 623,3 & 0,294 \\
\hline Phosphorus (mg) & $1624 \pm 736,8$ & 568,9 & 2591,1 & $1304 \pm 1291$ & 487,6 & 13355 & 0,105 \\
\hline Iron (mg) & $13,5 \pm 6,1$ & 7,1 & 26,4 & $10,6 \pm 3,4$ & 4,5 & 20,1 & 0,020 \\
\hline Zinc (mg) & $14,2 \pm 7,8$ & 4,4 & 30,4 & $10,1 \pm 4,1$ & 3 & 23,2 & 0,008 \\
\hline
\end{tabular}




\section{A. Humeyra Islamoglu et al.,/2019}

Table 4 Evaluation of nutrition knowledge levels of trainers and individuals doing sports

\begin{tabular}{lcccccc}
\hline $\begin{array}{l}\text { Nutrition } \\
\text { Knowledge }\end{array}$ & \multicolumn{2}{c}{ Sports Trainers } & \multicolumn{2}{c}{ Individuals Doing Sports } & \multicolumn{2}{c}{ Total } \\
\hline & $\mathrm{n}$ & $(\%)$ & $\mathrm{n}$ & $(\%)$ & $\mathrm{n}$ & $(\%)$ \\
Poor & 2 & 20.0 & 4 & 4.0 & 6 & 5.5 \\
Average & 6 & 60.0 & 50 & 50.0 & 56 & 50.9 \\
Good & 1 & 10.0 & 37 & 37.0 & 38 & 34.5 \\
Excellent & 1 & 10.0 & 9 & 9.0 & 10 & 9.1 \\
Total & 10 & 100.0 & 100 & 100.0 & 110 & 100.0 \\
\hline
\end{tabular}

Table 5 Correlation between YETBID Scale scores and energy, macronutrient intake and BMI of participants

Energy \& Macronutrients Intakes and BMI
Score of YETBID Scale

\begin{tabular}{cc}
\hline & $\mathrm{p}$ \\
\cline { 2 - 2 } Energy & 0,919 \\
Protein & 0,211 \\
Fat & 0,340 \\
Carbohydrate & 0,210 \\
BMI & 0,140 \\
\hline
\end{tabular}

\subsection{Energy and Nutrient Intakes}

In Table 3, daily energy, macro and micro nutrient amounts of sports trainers and athletes are given. While there was a significant difference between energy intakes, no significant difference was observed between trainers and individuals doing sports in terms of meeting the macro nutrient requirements ( $p>0.05)$. In micronutrients; niacin, vitamin B12, iron and zinc intakes were significantly different between trainers and individuals doing sports

Table 4. shows the categorized YETBID Scale scores of sports trainers and individuals doing undergraduate and higher education. In this context, sports. The mean total score of YETBID scale of the a significant relationship was found between sports trainers participating in the study were educational status and scale scores $(p=0,02)$. $50.2 \pm 10.5$, and that of the individuals doing sports

was $55.3 \pm 6.96$. When the scale scores of the participants were expressed as percentages, the average scale score of the sports trainers was found to be $62.5 \%$, for individuals doing sports was $69.1 \%$ and the overall average score was found to be $68.5 \%$. When the scale scores of sports trainers and individuals doing sports were compared, it was found that the total score of individuals doing sports was significantly higher than sports trainers' $(p=0.037)$. The majority of sports instructors and individuals doing sports have received

\footnotetext{
s
} 


\section{A. Humeyra Islamoglu et al.,/2019}

In Table 5 the correlations between YETBID nutrition information flow between trainers and scores and intakes of energy, protein, fat, individuals.

carbohydrate, BMI values were shown. There was no significant relationship between energy and macronutrient intake levels, BMI values and scale score $(\mathrm{p}>0.05)$.

\section{Discussion}

Nutritional knowledge level is one of the main factors affecting the nutritional status and habits of individuals, families and communities [9]. It is known that an athlete's failure to consume sufficient energy and macro-nutrients may hinder the athlete's adaptation to training. At the same time, it has been proved that a balanced nutrition program that meets the energy requirements can increase the adaptation of the athlete's training [6].

In this study, it was found that $55 \%$ of individuals doing sports and $90 \%$ of sports trainers skipped meals; and it was found that $77 \%$ of sports trainers skipped lunch. However, considering main meal consumptions of the trainers, no skipping was observed. The lack of sufficient time of the trainers due to working conditions was determined as the main reason for skipping meals. In a study by Merkiel and Ratajczak, when the number of meals of female fitness participants was examined, it was observed that none of the participants consumed less than three meals a day. Almost all of the female fitness trainers find three meals a day to be correct, but they are insufficient in practice; they stated that the most important reason for this was compulsory training hours [10]. It was observed that the sport trainers participating in our study and the fitness trainers participating in the study of Merkiel and Ratajczak showed similarities in terms of the meal skipping habits and the number of skipped meals.

When the daily energy intakes were assessed, it was found that $80 \%$ of sports trainers and $72 \%$ of individuals doing sports get sufficient energy. A significant difference was found when the energy intakes were compared $(p=0,042)$. Macro and micronutrient intake levels of trainers and individuals doing sports were found to be similar (except the intakes of niacin, vitamin B12, iron and zinc). The reason for this is thought to be the
According to the answers given to YETBID scale, the mean scores were 50.2 for the sports trainers and 55.3 for the individuals doing sports. The majority of participants were undergraduate or graduate. In Devlin and colleagues' study about the sports nutrition knowledge levels of football and soccer players; the median score for overall sports nutrition knowledge was found to be $54.4 \%$ [11]. In a study in which Portuguese athletes' nutrition knowledge levels were assessed, it was found that only $8 \%$ of the athletes had good knowledge on nutrition and the overall mean knowledge score was found to be $49.8 \pm 14.9$ [12].

Furthermore, in our study, a significant relationship was found between educational status and scale scores $(p<0.05)$. In a study about the nutrition knowledge levels of high school coaches, Couture et al. found that the correct answer percentage of coaches to nutritional questions was $68.4 \%$. In addition, it was found that the education level of the coaches influenced the nutritional knowledge level, and university graduates scored higher than high school graduates [13]. From this perspective, our study is similar to the literature.

In addition, there was no significant relationship between energy, macronutrient intake levels, BMI values and scale score $(p>0.05)$. In contrast to this study, in a systematic review conducted in 2011; when the general and sportspecific nutritional knowledge levels of recreational and elite athletes were evaluated, it was found that $45-65 \%$ of the respondents answered the questions correctly and there was a weak positive relationship between nutritional information and adequate nutrient intake of athletes [14]. When two studies were compared; although the nutritional knowledge levels of the trainers and individuals doing sports were higher than those of recreational and elite athletes, there was no correlation between nutritional status and intake.

\section{Conclusion}

It was observed that the number of main meals of sports trainers and individuals doing sports 


\section{A. Humeyra Islamoglu et al.,/2019}

was similar. Significant differences were found between these two groups in terms of energy and some micro-nutrient intakes (niacin, vitamin B12, iron and zinc), whereas no significant difference was observed in terms of macro-nutrients. According to the YETBID Scale scores, a significant difference was observed between the sports trainers and individuals doing sports. In this study, it was found that nutritional knowledge levels of sports trainers and individuals doing sports did not affect their nutritional status. As a result, it was concluded that dietitians should be present at sport centers and nutrition trainings should be arranged in order to prevent improper nutrition practices.

\section{References}

[1] J.A. Nogueira, T.H. Da Costa, Nutritional status of endurance athletes: what is the available information?, Archivos Latinoamericanos de Nutrición, 55 (2005) 15-22.

[2] Y. Özdoğan, A. Özfer Özdoğan, Evaluation of the nutrition knowledge of sports department students of universities, Journal of the International Society of Sports Nutrition, 8 (2011) 11.

[3] S. Sceery, Nutritional Impact on Performance in Student-Athletes: Reality and Perception, Health Sciences Student Work, 2017.

[4] S. Holden, B. Forester, A. Smith, C. Keshock \& H. Williford, Nutritional Knowledge of Collegiate Athletes, Applied Research in Coaching and Athletics Annual, 33 (2018) 6577.

[5] B.A. Mitchell, S.L. Holden, B.E. Forester, L.R. Gurchiek, R.J. Heitman, Nutritional education intervention and the effects on nutritional knowledge of male college athletes, Applied Research in Coaching and Athletics Annual, 31 (2016) 207-223.

[6] Richard B Kreider, Colin D Wilborn, Lem Taylor, Bill Campbell, Anthony L Almada, Rick Collins, Mathew Cooke, Conrad P Earnest, Mike Greenwood, Douglas S Kalman, Chad M Kerksick, Susan M Kleiner, Brian Leutholtz, Hector Lopez, Lonnie M Lowery, Ron Mendel, Abbie Smith, Marie Spano, Robert Wildman, Darryn S Willoughby, Tim N Ziegenfuss and
Jose Antonio, International Society of Sports Nutrition exercise \& sport nutrition review: research \& recommendations, Journal of the International Society of Sports Nutrition, 7 (2010) 1-43.

[7] T.C. Ministry of Health, Türkiye Beslenme Rehberi/Turkiye Nutrition Guide (TÜBER), Ministry of Health Publishing, Ankara, 2015.

[8] H. Batmaz, Yetişkinler için Beslenme Bilgi Düzeyi Ölçeği Geliştirilmesi ve Geçerlik Güvenirlik Çalışması (Development of Nutrition Knowledge Level Scale for Adults and Validity and Reliability Study), Marmara University, Institute of Health Sciences, unpublished master thesis, 2018.

[9] Baysal A. Beslenme, Hatiboglu Printing and Publishing, 12th Edition, Ankara, 2011; 157235.

[10] S. Merkiel, M. Ratajczak, Food behaviour and attitude towards nutritional knowledge in female fitness instructors and female fitness participants, Roczniki Państwowego Zakładu Higieny, 64 (2013) 325-330.

[11] B.L. Devlin, M.D. Leveritt, M. Kingsley, R. Belski, Dietary intake, body composition, and nutrition knowledge of Australian football and soccer players: Implications for sports nutrition professionals in practice, International Journal of Sport Nutrition and Exercise Metabolism, 27 (2017) 130-138.

[12] R. Costa Pereira, G. Pitarma, M. Jardim, Evaluation of Portuguese athletes knowledge regarding nutrition and hydration in sports, Annals of Medicine, 51(sup1) (2019) 219.

[13] S. Couture, B. Lamarche, E. Morissette, V. Provencher, P. Valois, C. Goulet, V. Drapeau, Evaluation of Sports Nutrition Knowledge and Recommendations Among High School Coaches, International Journal of Sport Nutrition and Exercise Metabolism, 25 (2015) 326-334.

[14] G.L. Trakman, A. Forsyth, B.L. Delvin, R. Belski, A Systematic Review of Athletes' and Coaches' Nutrition Knowledge and Reflections on the Quality of Current Nutrition Knowledge Measures, Nutrients, 8 (2016) 570. 
Zeghari Lotfi et al.,//2019

\section{Funding}

This study was not funded by any grant

\section{Acknowledgements}

The authors would like to thank every participant for his effort and time.

\section{Conflict of interest}

None of the authors have any conflicts of interest to declare.

\section{Informed consent}

All participants gave written informed consent to participate in this study.

\section{About The License}

\section{()ㅜㅇ}

The text of this article is licensed under a Creative Commons Attribution 4.0 International License 